\title{
Otoplasty: New Modification of the Mustardé Technique
}

\author{
MOHAMED A.S.M. EL-ROUBY, M.D. \\ The Department of Plastic and Reconstructive Surgery, Faculty of Medicine, Ain Shams University, Cairo, Egypt
}

\begin{abstract}
Background: One of the most established techniques for management of protruding ears is the Mustardé technique (1). Many modifications had been published for this technique; however, all these modifications started by retro-auricular incision. We modify the Mustardé technique using three retroauricular microincisions to correct several deformities of the auricular cartilage in protruding ears.
\end{abstract}

Patients and Methods: 46 patients ( 7 unilateral, 39 bilateral) (85 ears) who were candidates for this technique, their age ( $25 \pm 2.8$ years), 38 males, 8 females. The operation time, steps, follow-up sessions ( 2 weeks, 3,6 and 18 months) data was recorded. Pre-operative and post-operative (1, 18 months) photos were compared and analyzed by custom made computer program the evaluated the results.

Results: 42 patients achieve a natural appearance. Extrusion of threads occurred in 8 ears. Asymmetrical ears were noticed in 4 patients and recurrence in 11 patients. These patients were revised by Mustardé technique with retroauricular incisions. None of the patients developed retroauricular scars.

Conclusion: This versatile modif ication allows for better asthenic results of otoplasty and minimizes complications of skin incision unless cartilage and/or skin resection is needed.

Key Words: Thread-Otoplasty - Prominent ear.

\section{INTRODUCTION}

The aesthetic and emotional impacts of protruded ears on the patient are considerable [2]. The curves of the ear are caused by the cartilaginous structure and the skin is just the covering. Many anatomical variations cause a protruded ear deformity. These anatomic variations may be present unilateral or bilateral, isolated or combiend. Basically, there are a defect in formation of Antihelical Fold and Conchal hypertrophy, and an increased conchomastoid angle $\left(>90^{\circ}\right)$ [3].

To correct these deformities, several techniques were well described (i.e., Mustardé, Furnas, and Stenstrom techniques), and each of it had its benefits and drawbacks. The authors constantly modify these techniques to enhance results and minimize recurrence. The choice of surgical technique should be customized to each patient according to meticulous preoperative assessment [4].
However, the minimally invasive techniques have more preferred to the patient and the doctor than the open techniques. The closed techniques for otoplasty minimize the risk of early complications like hematoma, infection, and necrosis of the cartilage and skin and late complications like longer-lasting head dressings, possible keloid scarring, hypoesthesia of the auricles [5-14].

The idea of this modification is to combine of Mustardé and Furnas techniques with minimal incisions. The described modification combines the aesthetic advantages of the suture technique with those of a scoring technique. It avoids the disadvantages of skin incisions like keloids and hypoesthesia.

\section{PATIENTS AND METHODS}

After the clinical evaluation and diagnosis of the deformity, we performed this technique on a series of 46 cases. Three cases of them had previously undergone otoplasty but complained of residual undesirable aesthetic features. They had one or more deformities (Conchal cartilage hypertrophy, ill-defined antihelical fold or obtuse choncomastoid angle). The patients were followed-up for 18 months ( 2 weeks, 3, 6 and 18 months). Preoperative and post-operative photos (1-18 months) were compared and analyzed by custom made computer program the evaluated the results.

\section{Surgical technique: (Available online [21]).}

All patients were operated on an outpatient basis, under local anesthesia, by infiltrating the ears with about $5 \mathrm{ml}$ of local anesthetic (lidocaine $1 \%$ with adrenaline 1:200,000). Each deformity should be corrected separately, with a specific incision and minimal dissection.

One to three microincisions $(2 \mathrm{~mm})$ with an 11gauge scalpel is/are placed in retroauricular crease (Fig. 1).

A custom curved syringe needle 28-gauge is used for cartilage scoring and passing Polypropyl- 
ene thread to fold cartilages (Fig. 2). The first step in each suture is to introduce the needle from the anterior aspect of the ear to get out through the retroauricular microincision (Figs. 3A,B). The thread is packed in the lumen of the needle. The needle is pulled out till its tip is just subcutaneously located (Figs. 4C,D). Then, the direction of needle tip is changed to noose the thread around the cartilage to go in direction of the microincision again. The thread two ends now could be pulled together after removing or the needle. After folding of the cartilage manually by the assistant to the predetermined degree, the suture is placed and buried in the depth.

We recommend the use of propylene $2 / 0$ suture as permanent suturing material with high tensile strength to avoid recurrence and minimize infection. Through the upper incision, the deformed antihelix is folded. The middle incision is used to place the concomastoid suture. The lower incision may be added in some cases to improve the aesthetic results especially if there is a hypertrophic scapha or lobule. The skin microincisions will heal by primary intension without any noticeable scars. Tie over dressing and the creep bandage are applied for five days. Systemic antibiotic and analgesic is administrated as prophylaxes for one week. The pressure garment is then applied for 3 months. The patients are instructed to avoid pulling out the ear especially during shaving.
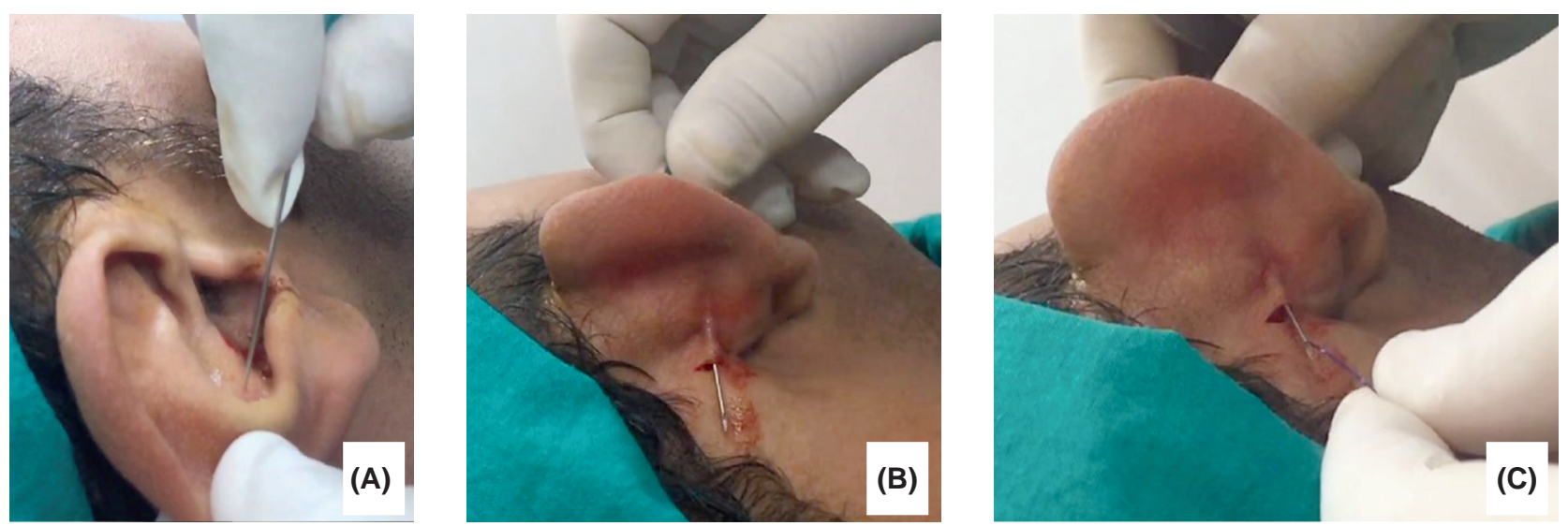

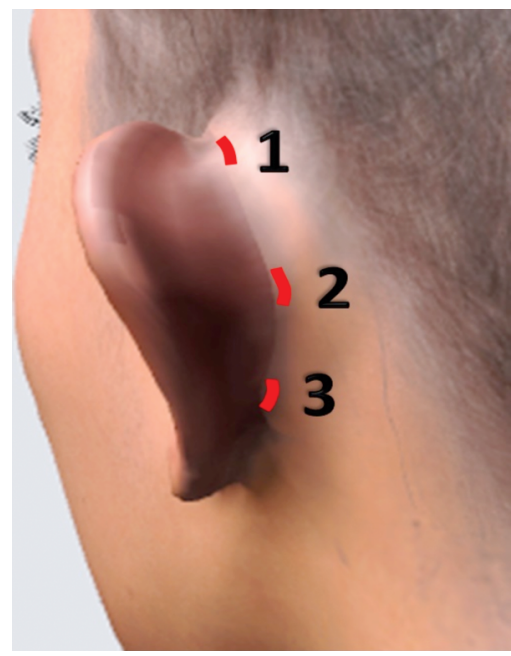

Fig. (1): Sites of upper, middle and lower microincisions in retroauricular crease.

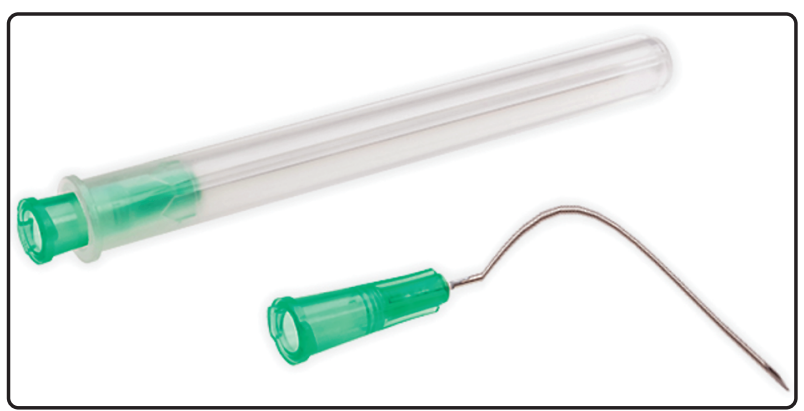

Fig. (2): The custom curved syringe needle 28G

(B)

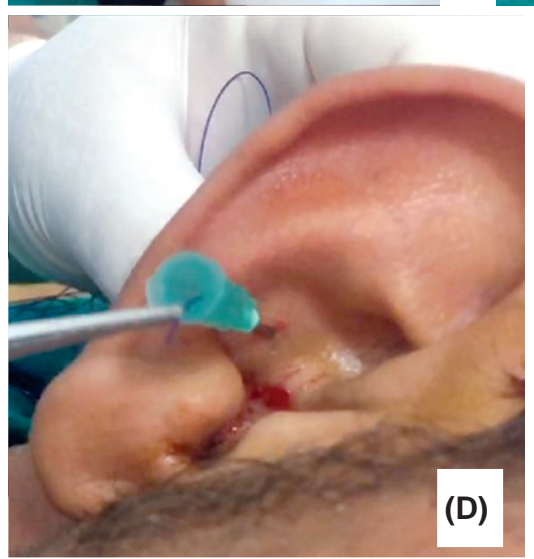

Fig. (3): (A) Piercing of the concal cartilage anterior aspect by the needle. (B) The tip of the needle gets out the middle microincision. (C,D) Packing of the propylene $2 / 0$ thread in lumen of the needle passing through the cartilage. 


\section{RESULTS}

The reported technique was performed in series of 46 cases ( 38 males, 8 females), ( 7 unilateral, 39 bilateral) (85 ears). Their age ranged from 2129 years ( $25 \pm 2.8$ years). The causes of the protrusion were ill-defined antihelical fold in 64 ears (75.2\%), obtuse choncomastoid angle in 73 ears $(85.9 \%)$ and conchal cartilage hypertrophy in 17 ears $(20 \%)$ (Fig. 4, Table 1). All the patients were scheduled to followed-up for 18 months, the shortest follow-up time was 3 months, the longest 45 months. The operative time was ranged from 54 to 90 minutes $(63 \pm 21$ minutes).

As regard the complications (Table 2), all ears had edema for 3-7 days postoperatively. Stitch sinus and extrusion of threads occurred in 8 ears (Fig. 5). They were managed by removal of the thread part of it and redo. Asymmetrical ears were noticed in 4 patients that needed retouch by redo or elliptical retroauricular skin excision. Recurrence of ear protrusion in 11 ears was repeated using classical Mustardé technique. There were 9 ears of post-operative hematoma, which was effectively controlled with evacuation and applying of tie over dressing for a week. One patient had bilateral skin necrosis of antihelix and exposed cartilage and was managed conservatively (Fig. 6). Two patients reported significant ear hypersensitivity over 4 months. No patients complained of Infection, hypoesthesia nor keloids scarring.
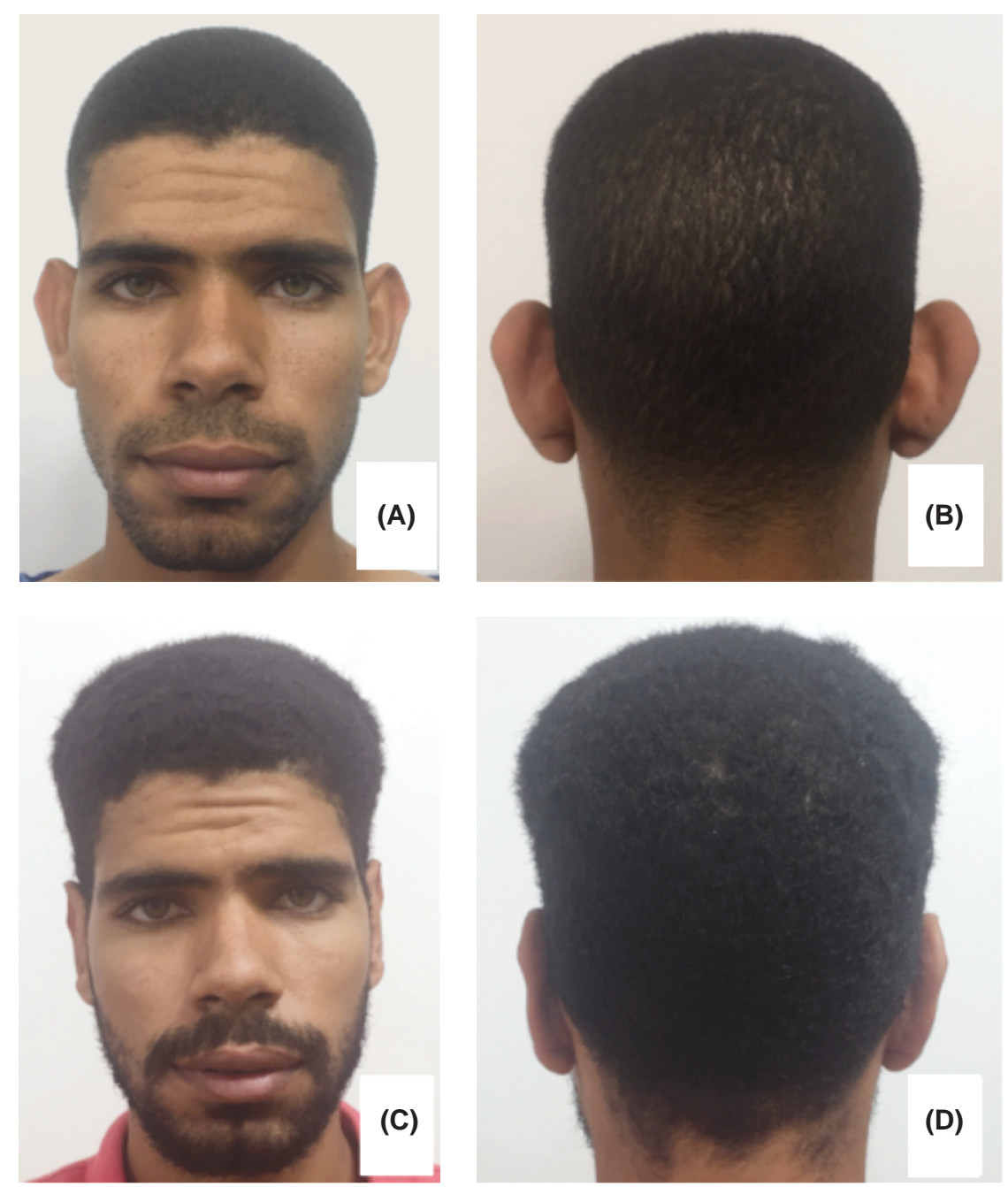

Fig. (4): Pre-operative front (A), Posterior (B) Views, postoperative 6 months front (C), Posterior (D) Views. 


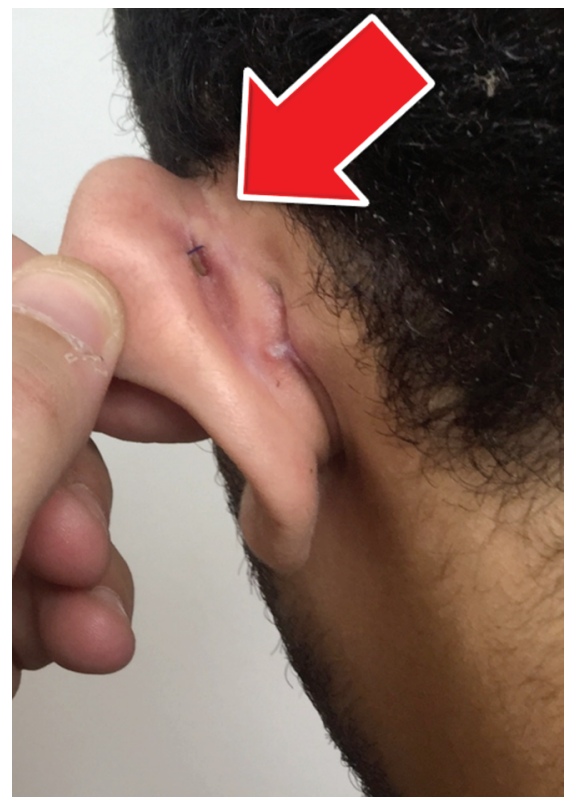

Fig. (5): Extruded thread.

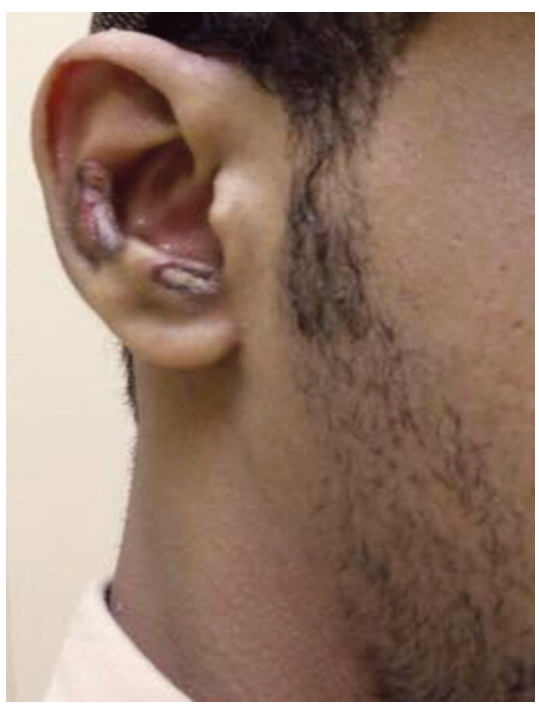

Table (1): Causes of ear protrusion.

\begin{tabular}{llc}
\hline & Cases & Percent \\
\hline Ill-defined antihelical fold & 64 ears & 75.2 \\
Obtuse choncomastoid angle & 73 ears & 85.9 \\
Conchal cartilage hypertrophy & 17 ears & 20 \\
\hline
\end{tabular}

Table (2): Complications.

\begin{tabular}{llc}
\hline Complication & Number & Percent \\
\hline Hematoma & 9/85 ears & 10.6 \\
Stitch sinus and extrusion of threads & 8/85 ears & 9.4 \\
Recurrence & 11/85 ears & 12.9 \\
Asymmetrical & $4 / 46$ patients & 8.7 \\
Ear hypersensitivity & $2 / 46$ patients & 4.3 \\
Skin necrosis & $1 / 46$ patients & 2.1 \\
Infection & 0 & \\
Hypoesthesia & 0 & \\
Keloids or hypertrophic scarring & 0 & \\
\end{tabular}

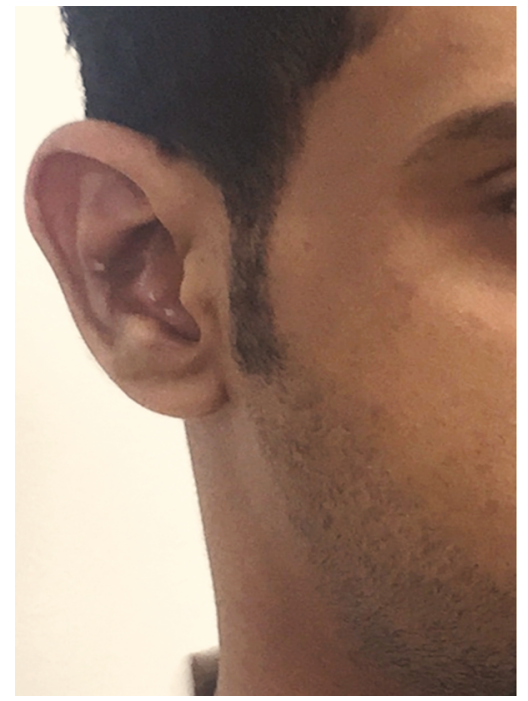

Fig. (6): Sequence of antihelix skin necrosis due to aggressive pressure that was managed conservatively ( 3 months, 6 months post-operatively).

\section{DISCUSSION}

The goal of otoplasty is creation of symmetric, well-shaped, and natural-appearing ears [15]. With era of non-surgical aesthetic procedures, many patients ask for minimal invasive techniques to improve their body image [7]. To achieve best aesthetic results in otoplasty, plastic surgeons should understand the most common postoperative complaints among recurrent otoplasty and to keep in mind which aesthetic parameters are relevant to the patients $[2,3,16]$.

As far as we know, Kaye [17] introduced a closed method for correcting protruding ears. It combined Mustardé [1] and Stenström's [18] principles. Kaye initially placed the knots on the front of the anthelix, but in 1973 put the dorsally. To further reduce the tendency for recurrence, he undermined the dorsal skin in the course of the anthelix, with the intention of creating a dorsally directed scar train. Kaye did not detail his clinical findings.

Peled [5] published the idea of Knifeless otoplasty and Fritsch [6] described the Incisionless otoplasty, and revised the technique [8,9]. Fritsch [11], applied his technique in protuberant lop ear. Fritsch described his techniques as retention suture for the antihelix and extend to the conchal bowl 
and the lobule. He depended on stitch fibrous tracks to maintain the shape of bended cartilage but did not apply it to correct obtuse concomastoid angle [13].

Nikolay [19] stated that "closed approach transcutaneous Serdev Suture ${ }^{\circledR}$ lifts encompass the principal concept of suture suspension and/or repositioning". Nikolay uses Deschamps Aneurysm Needle (30-gauge), which is more traumatizing than the custom curved syringe needle (28-gauge) which used in the reported technique. Both needles could be used for passing threads and scoring of the cartilage.

Merck, took up Peled's method with a modification of the thread guide, dorsal placement of the knots and no processing of the cartilage, but this technique, four-in-one mattress suture to bend the ill-defined antihelix, did not correct other deformities of the ear as concal hypertrophy nor concomastoid angle [12,14].

There are many advantages of the reported technique: Applicable to all ages, local anesthesia can be used, short operative time, hidden suture, direct control of ear contours, easy and rapid correction of an ill-defined antihelical fold, easy adjustment of concomastoid angle and avoid complications of open techniques as infection, hematoma, asymmetry and risk of keloid and hypertrophic scarring [20]. However, the main disadvantage is inability to resect the hypertrophied conchal cartilage or excess retroauricular skin if needed [10].

To avoid local foreign body reactions of the suture materials, we used the monofilament materials propylene $2 / 0$. In addition, because their relatively rigid knot ends that predisposed to skin perforation, we placed the knots on the back of the auricle, as far as possible deeper and medially, in the retroauricular crease.

\section{Conclusion:}

The reported technique is applicable to correct many anatomical variations of the ear unless cartilage and/or skin resection is needed. It could be done under local anesthesia as outpatient. The complications reported is lesser than that of other open techniques especially retroauricular scars with similar aesthetic results because there is no skin incision nor aggressive dissection.

\section{Disclosures:}

The author has no disclosures with respect to the contents of this article.

\section{REFERENCES}

1- Mustarde J.C.: The correction of prominent ears using simple mattress sutures. British Journal of Plastic Surgery, 16: 170-8, 1963.

2- Janis J.E., Rohrich R.J. and Gutowski K.A.J.P.: Surgery R. Otoplasty, 115 (4): 60e-72e, 2005.

3- Ribeiro J.A.S. and Silva G.S.D.J.A.P.S.: Finesse in Otoplasty in Four Steps, 36 (4): 846-52, 2012.

4- Petersson R.S.: Current Trends in Otoplasty. Advanced Cosmetic Otoplasty: Springer, p. 65-80, 2013.

5- Peled I.J.J.A.P.S.: Knifeless otoplasty: How simple can it be?19 (3): 253-5, 1995.

6- Fritsch M.H.J.T.L.: Incisionless Otoplasty, 105 (S70): 111, 1995.

7- De La Fuente A. and Santamaria A.J.E.J.O.P.S.: Minimally Invasive Otoplasty, 21 (5): 249-53, 1998.

8- Fritsch M.H.J.F.P.S.: Incisionless Otoplasty, 20 (04): $267-$ 70, 2004.

9- Fritsch M.H.J.O.C.O.N.A.: Incisionless Otoplasty, 42 (6): 1199-208, 2009.

10- Benedict M. and Pirwitz K.U.J.H.: Minimal invasive Otoplastik Minimally Invasive Otoplasty, 53 (3): 2307, 2005.

11- Fritsch M.H.: "Incisionless Otoplasty": Anlegen des Cavum conchae ohne HautschnittIncisionless otoplasty with conchal bowl recession. J. HNO, 60 (10): 856-61, 2012.

12- Merck W.J.J.f.Ä.C.: Die Fadenmethode nach Dr. Merck, 6 (4): 209-20, 2013.

13- Fritsch M.H.: Incisionless Otoplasty zur Ohrmuschelkorrektur ohne Hautschnitt-die Technik von Fritsch. In: Bumm K, editor. Korrektur und Rekonstruktion der Ohrmuschel. Berlin, Heidelberg: Springer Berlin Heidelberg, p. 145-51, 2017.

14- Merck W.H.: Ohrmuschelkorrektur ohne Hautschnitt-die Fadenmethode von Merck. Korrektur und Rekonstruktion der Ohrmuschel: Springer, p. 153-69, 2017.

15- Miyamoto J., Nagasao T., Tamaki T. and Nakajima T.J.P.: Surgery r. Biomechanical evaluation of surgical correction of prominent ear, 123 (3): 889-96, 2009.

16- Kelley P., Hollier L. and Stal S.J.J.O.C.S.: Otoplasty: Evaluation, technique, and review, 14 (5): 643-53, 2003.

17- Kaye B.L. and Kaye B.L.J.P.: Surgery r. A simplified method for correcting the prominent ear, 40 (1): 44-8, 1967.

18- Stenstrom S. and Heftner J.: The Stenstrom otoplasty. J. Clinics in Plastic Surgery, 5 (3): 465, 1978.

19- Serdev N.: Serdev Sutures ${ }^{\circledR}$ in Upper Face: Brow and Temporal Lift; Glabella Muscle Ligation. Miniinvasive Face and Body Lifts-Closed Suture Lifts or Barbed Thread Lifts: In Tech, 2013.

20- Owsley T.G. and Biggerstaff T.G.J.O.: America mscoN. Otoplasty complications, 21 (1): 105-18, 2009.

21- https://youtu.be/meM2LlzO4DM. 